\title{
Health and Healthy Lifestyle as Social Values of State Development
}

\author{
Rezer Tatiana ${ }^{1 *}$
}

\begin{abstract}
${ }^{1}$ Department of Theory, Methodology and Law Support of State and Municipal Administration, Ural Federal University named after the first President of Russia B. N. Yeltsin, Yekaterinburg, Russian Federation

${ }^{*}$ Corresponding author. Email: t.m.rezer@urfu.ru
\end{abstract}

\begin{abstract}
The article considers the theoretical and methodological justification of two categories: 'health' and a 'healthy lifestyle' as social values of the state development based on the adopted social policy in this sphere. The author considers the process of the health and healthy lifestyle values formation as the highest goals and values of the state in the adopted normative legal acts of Russia. The comparative analysis has shown that the definition of the 'healthy lifestyle' category emphasizes different aspects of the development of social values and their impact on the development of the state policy in this sphere. The article substantiates that this process runs if the realization of goals and values occurs at three levels: personal or individual level; collective or community level; state or political level. The author used the social approach to identify the consequences of the implementation of the state's social policy in the sphere of a healthy lifestyle on the value attitude of people to their health and elements of a healthy lifestyle culture. It was revealed that the number of smokers aged 16 to 18 years has sharply decreased from $24 \%$ to $5 \%$ of smokers in this age category, which confirms the correctness of the conclusions about the need for the three-level awareness of goals and values in the field of a healthy lifestyle. The author used the legal approach to analyse the achievement of targets in the field of a healthy lifestyle based on legal acts. Over the past decade, Russia has developed a sufficient legal framework in this sphere.
\end{abstract}

Keywords: health, a healthy lifestyle, category, social policy, social values, levels of development of social values in the field of a healthy lifestyle, the highest goals, the values of the state

project "Healthy Lifestyle", which is an integral part of another national project "Demography".

\section{INTRODUCTION}

Recent developments in the Russian healthcare sector and society have been caused by the spread of the fight against COVID-19 and served as a reference to the research topic. It would be wrong to say that Russia was not ready to fight the COVID-19 pandemic because it was the first time when medical workers in their professional activities, as well as ordinary citizens, face the infection. Therefore, it became interesting for us to consider the social policy of Russia as a socially-oriented state in terms of health and healthy lifestyle categories.

The priority on the formation of a healthy lifestyle of Russians is embodied in the Concept of Long-Term SocioEconomic Development of the Russian Federation for the Period up to 2020, in the fundamentals of the state policy of the Russian Federation in the field of healthy nutrition of the population for the period up to 2020, the Decree of the President of Russia from May 72018 "On the national goals and strategic tasks of the development of the Russian Federation for the period up to 2024". The healthy lifestyle is positioned as one of the national goals of the federal

\section{LITERATURE REVIEW}

We want to start with the 'health' category. A healthy lifestyle is aimed at ensuring and maintaining health. The concept of 'health' has many definitions, but most often researchers focus on the definition given by the World Health Organization. As it was defined by the World Health Organization, 'health' is a state of complete physical, mental, and social wellbeing and not merely the absence of disease or infirmity.

Several definitions of health emphasize certain characteristics of this phenomenon. For example, health as the absence of diseases and an ideal state of well-being is very rare in reality. Health is a balance (the so-called dynamic point of view), a person has certain reserves of the body, which he must rationally use during life and achieve results.

Mental health is an individual's viability. In Russian science, one of the definitions of health is based on the theory of needs. Health refers to the ability of a person to meet his or her material and spiritual needs. To be healthy, 
it is necessary to teach a child or an adult to be aware of personal needs and meet them, while not violating the rights and space of other people. Experts of the World Health Organization focus on two parts of health protection:

- $\quad$ prevention of diseases and injuries;

- taking measures for solving existing problems by the state [1].

Generally, a lifestyle is a set of forms of human activity that manifests itself in everyday life, work, culture, behaviour. Through the evaluation of a lifestyle, it is possible to determine the level of the development of society and the presence of dominant values [2].

If we compare the 'lifestyle' and 'health' categories with each other, we can deduce the 'healthy lifestyle' category. It should include everything that is aimed at performing a person's professional, social, and household functions in the most favourable conditions for human health and the development of a person as an individual who understands the values of his or her health and the importance of health for the effective life.

The comparative analysis has shown that when defining the 'healthy lifestyle' category, different aspects of this research object are emphasized. According to A.V. Kryuchkova, A.M. Knyazeva, A.V. Knyazev, a healthy lifestyle is a prerequisite for the development of various aspects of human life, achieving active longevity and fullfledged performance of social functions, for active participation in labour, social, family, household and leisure forms of life [3].

The following elements are distinguished in a healthy lifestyle:

- $\quad$ organization of food, sleep, outdoor activities that meet the requirements of sanitary and hygienic standards; organization of individual appropriate mode of motor activity;

- culturally meaningful leisure that has a developing impact on a person and personality;

- $\quad$ avoiding bad habits;

- culture of sexual relations and interpersonal behaviour in a community;

- $\quad$ self-affirmation and self-organization in activities, based on a value attitude to health [4].

In our view, the lives of young people, as well as the lives of all people, regardless of their age, are determined by the conditions of the society in which they live. The development of young people, their social status, the nature of their daily life, their aspirations, opportunities, and health depend on, most of all, the nature and social conditions of life $[5,6]$. Social conditions are established by the social policy implemented by the state in the sphere of a healthy lifestyle.

A.V. Martynenko points out that the preference for a healthy lifestyle is a cultural component indicating the degree of socialization of an individual in a society, which includes a personal healthy attitude of that individual; life activities aimed at such types of health as mental, physical, moral; support for internal health factors, which consists of observing the daily routine, diet, healthy habits, motor activity, etc. [7]. We agree with the statement that the way of life is influenced by social norms and laws adopted in the country.

A healthy lifestyle is a kind of behavioural response, as well as a human activity, the essence of which is to prevent diseases and promote health. Statistical data show that 100 $\%$ of human health is determined by $50-55 \%$ of a lifestyle, $20 \%$ depends on the environmental conditions, $18-20 \%$ is defined by genetic predisposition and only $8-10 \%$ is the result of the activities of the health services [8].

At the same time, the key risk factors that worsen health and should be prevented when choosing a healthy lifestyle are: smoking, drinking many doses of alcohol, lack of physical activity and sports in a person's life (passive lifestyle), drug addiction, improper nutrition (the predominance of fast food, fatty, fried, excessively highcalorie food), promiscuous sexual relations [9].

Considering the content of social policy in the field of healthy lifestyles, we found out that social policy in the sphere of healthy lifestyles is a part of the activities of the social state, in which various spheres of public life are arranged concerning the moral principles of social justice and social solidarity, aimed at creating conditions that allow everyone to lead a decent lifestyle, develop freely, receive social benefits guaranteed by the state, and fulfil obligations to society. The principles of social policy are approved in specific decisions of public administration bodies and are implicated by laws.

\section{METHODOLOGY OF THE RESEARCH}

In the study, we used an analysis method to determine the main directions of the social policy in the field of a healthy lifestyle, conducted by the state at different levels of government.

The method of the comparative analysis, as an interdisciplinary research method, allowed us to determine the general thing that defines the 'healthy lifestyle' and 'health' categories. It is established that the social policy in the sphere of a healthy lifestyle is effective if there is a value of awareness of health at three levels:

- a personal level, it is an individual level of health of a person;

- a collective level, it is a level of community, the health of the population in a particular area of a shared accommodation or joint work in a firm or enterprise;

- a state-political level, it is politically responsible decisions made at the level of goals and values in the field of health preservation and it has a national character and development strategy.

The author used the social approach to identify the consequences of the implementation of the state's social policy in the field of a healthy lifestyle and the revision of the value attitude to health at the personal level and to identify elements in the healthy lifestyle behaviours.

The author also used the legal approach to get a general pattern of the documents adopted by the state in the field of 
a healthy lifestyle and analyse the achievement of targets in the adopted projects and programs.

\section{RESEARCH RESULTS}

The key functions of the state include ensuring a safe living environment, maintaining an appropriate level of environmental safety, monitoring the production and sale of food that meets the requirements of environmental and food safety, providing qualified primary health care, providing social protection in difficult life situations, monitoring compliance with safety and labour protection at work, etc. The basis for the state policy in the field of a healthy lifestyle is the legal framework, which includes the regulation of environmental factors (water, air, soil, housing, etc.) that affect the health of the population, control over the provision of medical care and medical services that ensure environmental safety and supervision.

The experience of many developed countries shows that targeted policies of public authorities that promote a healthy lifestyle can lead society to the desired results and its development.

The formation of a healthy lifestyle and its promotion should be primarily engaged in the education system, which enables to include this issue in the development programs of pre-schoolers, schoolchildren, and students. The introduction of such programs may allow reaching an individual level of awareness of the value of health as a resource that can achieve any goals. Therefore, the formation of students' readiness for activities aimed at preserving health as a value is the main task of modern schools in Russia [10].

At the collective level, or the community level, the awareness of values in the field of healthy lifestyle occurs when projects are adopted by state and municipal authorities at the city and village level, that is, at the level of the territorial community.

For example, the "Healthy Cities" project held under the auspices of the European Regional Office of the World Health Organization, is being implemented in the cities of Cherepovetz, Veliky Ustyug, Cheboksary, Novocheboksarsk, Izhevsk, Stavropol, Samara, Yakutsk, and Ulyanovsk. Within the framework of the Healthy Cities project, work is being carried out in the following directions:

- 'healthy' urban planning,

- health at old age,

- the active lifestyle.

The formation of a responsible attitude to the health of the population, support against tobacco smoking, alcohol and drug abuse, provision of conditions for a healthy lifestyle, correction and regular monitoring of behavioural and biological risk factors for non-communicable diseases are defined at the group and individual levels, which makes this project to be mass and significant.

The political level is the level of the state administration, where the highest goals are defined; these are the values of the state in preserving human potential. This level is characterized by state guarantees, namely, obligations assumed by the state for its citizens. Obligations are always fulfilled if they are in the form of law and are socially oriented.

The basis for the state policy in the sphere of a healthy lifestyle is the Concept of Long-Term Social and Economic Development of the Russian Federation for the Period up to 2020.

"Principles of State Policy in the Field of Healthy Nutrition of the Population of the Russian Federation for the Period up to 2020" were adopted and implemented.

There were developed and approved norms of physiological needs for energy and nutrients for different population groups of the Russian Federation and the Order of the Health Ministry of Russia dated 02.08.2010 No. $593 \mathrm{H}$ approved "The Recommendations for Rational Norms of Food Consumption", which meet modern requirements of healthy eating.

The Ministry of Health of Russia and the Russian Academy of Medical Sciences established an advisory and diagnostic centre "Healthy Nutrition" based on the AllRussian State Centre of the Quality and Standardization of drugs and the Scientific Research Institute of Nutrition of the Russian Academy of Medical Sciences. A network of consulting and diagnostic centres for "Healthy nutrition" has been established in federal districts and regions of the Russian Federation. The main focus of these centres is the promotion of healthy and dietary nutrition and the fight against obesity.

In 2017 the passport of the priority project "The Formation of a Healthy Lifestyle" was approved. The project implementation period is from July 2017 to 2025 .

At the regional level, Russia also implements programs for promoting a healthy lifestyle. Among the programs, we can highlight one project. It is "The Promotion of Healthy Lifestyle among the Population of the Samara Region". People grafted the values of a healthy lifestyle, conducted interactive sessions on health protection, the active coverage of this issue in the media, organizes school and student activities to spread the values of health and a healthy lifestyle.

The Tyumen region has approved and is implementing a regional target program "The Formation of a Healthy Lifestyle and Prevention of Non-communicable Diseases of the Population in the Tyumen region", it is developed for 2018-2025.

In the Chuvash Republic, "The Formation of the System of Motivation of Citizens to a Healthy Lifestyle, including Healthy Nutrition and Rejection of Bad Habits" project is 
being implemented. It was adopted in 2019 and has great public support.

The Tomsk region is implementing "The Strengthening Public Health" project, which was adopted in 2019 and is expected to be held until 2024. The project is purposefully dedicated to the formation of a value attitude to the health of citizens.

Also, the all-Russian competition, named "Healthy Russia", is being held, dedicated to the issues of a healthy lifestyle of the population. The competition was established by the Ministry of Health of the Russian Federation as part of the state communication program for the formation of a healthy lifestyle among the population of the Russian Federation. The competition is held to promote the formation and dissemination of healthy lifestyle priorities among the population of the Russian Federation to strengthen individual health and health at the population level.

Within the framework of the "Healthy Russia" contest, seven categories and directions were defined:

- The Best Regional Project: projects aimed at promoting a healthy lifestyle of the region's residents (the region as whole or several districts) are accepted;

- The Best Municipal Project: projects aimed at promoting a healthy lifestyle of city residents (the entire city, city district, and even a separate yard) are accepted;

- The Best Rural Project: projects aimed at promoting a healthy lifestyle in rural areas are accepted;

- The Best Corporate Project: business projects aimed at creating a healthy lifestyle for employees of companies, as well as the local communities in which these companies work are accepted;

- The Best Youth Project: projects for creating a healthy lifestyle culture among young people and spreading the values of health and a healthy lifestyle are accepted;

- The Best Media Project: media projects for systematic coverage of the problem of a healthy lifestyle and value attitude to health are accepted;

- The Best Internet Project: projects on the Internet, including the creation of virtual communities operating on the Internet (using blogs, social networks, etc.) and aimed at creating a healthy lifestyle, or the introduction of healthy lifestyle ideas into those communities are accepted.

Thus, it can be concluded that at present the formation of a healthy lifestyle has become a priority of the Russian state in the social sphere and is recorded in the strategic documents of the Russian Federation, including "The Concept of the Long-Term Social and Economic Development of the Russian Federation for the Period up to 2020" and "The Concept of Health Development of the Russian Federation up to 2020".

There is the state program of the Russian Federation "Development of Health Care". We can consider it as the most important direction of policy in the field of health protection.

In 2019 the Federal State Statistics Service developed a methodology for calculating the indicator "The share of citizens who lead a healthy lifestyle" and in the same year evaluated this indicator [11]. The survey was conducted in August 2019 in 60000 households among all household members. It was attended by more than 131000 people, 56 $\%$ of them are female and $44 \%$ are male.

The calculation was based on a multi-purpose territorial sample based on the results of the 2010 census of the entire territory of Russia. The number of participants for each region was determined in proportion to the population. It turned out that most of the healthy lifestyle supporters live in the Republic of Ingushetia (48.8\% of respondents). Crimea has the second place (29.2\% of respondents), and Adygea has the third place (28.8\% of respondents).

At the top, five Chuvashia ( $24.7 \%$ of respondents) and the Voronezh region (24.2\% of respondents) are included. In Moscow, those who avoid bad habits and eat healthy food were ranked as $8.8 \%$ of the respondents, in Saint Petersburg it is only $6.8 \%$ of respondents. The Chukotka Autonomous Okrug became the outsider of the rating because only $0.4 \%$ of respondents follow the principles of a healthy lifestyle there.

For several years the Russian News Agency has been rating Russian regions for their commitment to a healthy lifestyle. Regional data for 2017-2018 are: in 2018 it was led by Dagestan, Chechnya, and Kabardino-Balkaria.

\section{CONCLUSION}

Our analysis of legal sources and social policy has shown that one of the harmful problems in the sphere of a healthy lifestyle is smoking. This conclusion is confirmed by static data.

1) In Russia, since 2009 young people have started smoking almost three times less, and the number of smoking adults has decreased by a third. Currently, $51 \%$ of men and $14 \%$ of women smoke in Russia. Among teenagers, the number of smokers is $15 \%$, which requires further active work in this direction at all levels.

2) The percentage of smokers aged 16 to 18 years dropped sharply from $24 \%$ to $5 \%$ of smokers in this age category of respondents; from 18 to 24 years - from $43 \%$ to $20 \%$ of respondents; from 25 to 34 years - from $44 \%$ to $37 \%$ of respondents.

3) The "Romir" Research Holding continues to study the behaviour of smokers in Russia with the support of the Fund of the Association of Physicians of Russia. Experts have established how many citizens in Russia want to give up smoking. The data shows that $77 \%$ of Russians tried to give up smoking. The main reasons for these are a concern for their health (92\% of respondents) and economic reasons ( $48 \%$ of respondents indicated that in the questionnaires). And a third of respondents are concerned about the health of others.

4) Last year the decline in the number of smokers has stopped. This was primarily due to the transition of cigarette smokers to hookahs, e-cigarettes, vapes, and tobacco heating systems. During the last two years, the number of 
smokers of alternative nicotine-containing products has increased from $4 \%$ to $11 \%$. Substitutes for classic cigarettes are especially popular among young people aged 18-24 years [12].

The 'health' and 'healthy lifestyle' categories have a common beginning because they are focused on the consciousness of the value of the most important human resource; we mean human life, which cannot be realized without the good physical and mental health of an individual.

The formation of an effective and efficient social policy in the field of a healthy lifestyle is possible at three levels: personal, collective, and state. For example, maintaining the health of students in Russian schools is impossible without the use of organizational and managerial aspects, including the organization of educational work based on the development of a value attitude to the health of future citizens of the country [13].

Unfortunately, health as a value does not always become the leading incentive in the lives of young people, which can be explained by the lack of sufficient social experience in life and the rejection of the basic values of the 'health' category [14].

The essence of the social state in the sphere of public health protection is the need to improve legislation at the federal and regional levels in the field of public health protection [15].

This process is possible through the implementation of the highest and most important goals, the values of the state, which contribute to the preservation of human potential and the development of the state itself

\section{ACKNOWLEDGMENT}

This work is a part of the grant from the School of Public Administration and Entrepreneurship of Ural Federal University "Development of social and value orientations of students of higher education in Russia and foreign countries in the context of digitalization of education".

\section{REFERENCES}

[1] G.S. Nikiforov, Z.F. Dudchenko, The concept of a healthy lifestyle: the history of formation, Scientific notes of the Saint Petersburg State Institute of Psychology and Social Work vol. 271 (2017) 99-106.

[2] S.A. Krylatov, Culture of a healthy lifestyle, in: Scientific notes of the Trans-Baikal State University. Series: Sociological Sciences (2013) 56-61.

[3] A.V. Kryuchkova, Healthy lifestyle - the right way to longevity, Applied information aspects of medicine 2 (2014) 92-98.

[4] T.G. Pestova, On the formation of students' value orientations in the sphere of sports and socialization in society, in: Sport and health, Russia, Saint Petersburg: Olimp SPb Publishing House (2005).

[5] T.M. Reser, Medico-social approaches to the organization of sexual education, Sociological Research 1 (2012) 102.

[6] T.M. Rezer, Professional education of the future specialist, Doctor 9 (2001) 45.

[7] A.V. Martynenko, Y.V. Valentik, V.A. Polessky, Formation of a healthy lifestyle of the youth, Moscow, Meditsina, 2008.

[8] The Proportion of citizens who lead a healthy lifestyle. The data of the Federal statistics, available online: https://www.fedstat.ru/indicator/59457

[9] Quality of life of Russians: key factors. Analytical review of VCIOM. Retrieved from: https://wciom.ru/index.php?id=236\&uid=9460

[10] N.V. Tretyakova, V.A. Fedorov, E.M. Dorozhkin, Student readiness formation for activities oriented to health saving, in: International Journal of Environmental and Science Education, 2016, vol. 11, no. 15, pp. 8281-8292. http://www.ijese.net/makale/1080

[11] The Proportion of citizens who lead a healthy lifestyle. The data of the Federal Statistics. Retrieved from: https://www.fedstat.ru/indicator/59457

[12] U. Bondarenko How many Russians tried to give up smoking. The Village, 2018, Retrieved from: https://www.the-village.ru/village/city/newscity/313207-kurenie..

[13] N.V. Tretyakov, V.A. Fedorov, E.V. Ketrish, O.M. Permyakov, Maintenance of Russian secondary school students' health (organizational and administrative aspect), in: International Journal of Engineering \& Technology 7(2) (2018) 13-17. https://www.sciencepubco.com/index.php/ijet/arti cle/view/11571/4487

[14] M.S. Khokholush, T.M. Rezer, On the development of value orientations of students of secondary vocational education, Education and science, Izvestiya UrO RAO 3 (27) (2004) 74-79.

[15] L.V. Zhilskaya, N.N. Zhilsky, Social policy for the protection and promotion of public health in the Russian Federation, Mir politiki I sotsiologii 9 (2012) 97-102. 